\title{
Interactive effects of crab herbivory and spring drought on a Phragmites australis-dominated salt marsh in the Yellow River Delta
}

\author{
Liwen Zhang a,e,f,*, Siqun Lan ${ }^{\text {a,b,e,f }}$, Christine Angelini ${ }^{c}$, Huapeng Yi ${ }^{\text {b }}$, Lianjun Zhao ${ }^{\text {a,be,e,f }}$, \\ Lin Chen ${ }^{\mathrm{a}, \mathrm{d}, \mathrm{e}, \mathrm{f}}$, Guangxuan Han ${ }^{\mathrm{a}, \mathrm{e}, \mathrm{f}, *}$
}

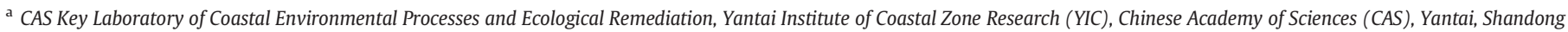
264003, PR China

b School of Resources and Environmental Engineering, Ludong University, Yantai, Shandong 264025, PR China

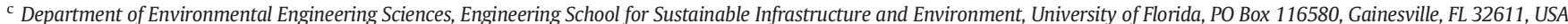

d College of Environment and Planning, Liaocheng University, Liaocheng, Shandong 252000, PR China

e Shandong Key Laboratory of Coastal Environmental Processes, YICCAS, Yantai, Shandong 264003, PR China

${ }^{\mathrm{f}}$ CAS Yellow River Delta Ecological Research Station of Coastal Wetland, YICCAS, Yantai, Shandong 264003, PR China

\section{H I G H L I G H T S}

- Quantify the importance of consumers on Phragmites in a salt marsh across temporal variation in abiotic stress.

- In the spring wetter year, Phragmites biomass were 75\% higher in Crab Exclusion relative to Ambient Crab plots.

- In the spring drought year, Phragmites biomass fell to $16 \%$ of levels of the spring wetter year in Ambient Crab plots.

- The magnitude of top-down control of Phragmites may be amplified with spring drought in salt marsh of the YRD.

\section{A R T I C L E I N F O}

\section{Article history:}

Received 4 August 2020

Received in revised form 25 November 2020

Accepted 26 November 2020

Available online 24 December 2020

Editor: Elena Paoletti

\section{Keywords:}

Top-down control

Salinity

Precipitation

Environmental change

Coastal wetland

Common reed

\section{G R A P H I C A L A B S T R A C T}

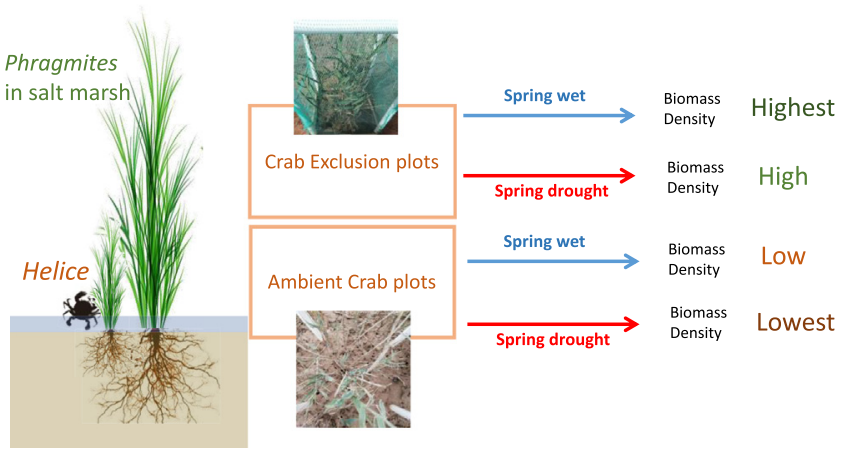

\begin{abstract}
A B S T R A C T
Consumers are often overlooked as key drivers of vegetation structure and ecosystem functioning in coastal wetlands. This oversight is particularly apparent in Asia, where much of the variation in coastal wetland plant growth and composition is attributed to physical stress gradients. To address this knowledge gap and quantify the relative importance of consumers in Asian coastal wetlands across temporal variation in environmental stress, we conducted a two-year experiment spanning relatively spring wet (2018) and spring dry (2019) years in which we manipulated the presence of the numerically dominant herbivorous crab, Helice tientsinensis, and evaluated its effects on Phragmites australis growth and structure in a Yellow River Delta salt marsh. In spring wetter 2018, Phragmites biomass and stem density were 75\% and 34\% higher in Crab Exclusion relative to Ambient Crab plots. In 2019 which experienced spring drought and elevated soil salinity, Phragmites biomass and stem density remained similarly high relative to 2018 in Crab Exclusion plots, but fell further, to only 16\% and 39\% of levels of 2018 observed in Ambient Crab plots. Phragmites' inflorescences density was also significantly reduced in Ambient Crab than Crab Exclusion plots in 2019. Together, these results highlight the significant role that crab herbivores can play in regulating Phragmites in Yellow River Delta salt marshes and suggest that the magnitude of their top-down control may be amplified, although in a non-additive manner, with spring drought stress in the region.
\end{abstract}

(c) 2020 Elsevier B.V. All rights reserved.

\footnotetext{
* Corresponding authors at: Yantai Institute of Coastal Zone Research, Chinese Academy of Sciences, Yantai 264003, PR China.

E-mail addresses: lwzhang@yic.ac.cn (L. Zhang), gxhan@yic.ac.cn (G. Han).
} 


\section{Introduction}

The concepts of bottom-up effect and top-down control of ecosystem structure and function have evolved and expanded over decades of ecological research. The bottom-up effect refers to the effects of abiotic factors, such as physical stress or resource supply (i.e. light, nutrient, salinity, flood, drought) on the fitness and distribution of plants. The effect of consumer feeding or behavior on the growth, reproduction and distribution of plants, in contrast, is referred to as the top-down effect (Bertness, 2007). The early discussion of "why the world is green" is indeed the debate of the relative importance of the bottom-up effect and top-down effect on the vegetation (Hairston et al., 1960; Murdoch, 1966; Oksanen, 1988).

Evidence from terrestrial, marine and coastal wetland ecosystems have revealed that top-down effects can be very important in regulating ecological processes (Poore et al., 2012; He and Silliman, 2016; Jia et al., 2018). Herbivory is the mechanism by which energy is transferred from primary producers to higher trophic levels, and is a key mechanism regulating the survival, growth, reproduction, population dynamics and community composition of the plants (Poore et al., 2012; He and Silliman, 2016; Jia et al., 2018; Mortensen et al., 2018; Chalifour et al., 2019). For terrestrial ecosystems, studies have found that herbivores reduced the survival, reproductive rate, biomass and abundance of terrestrial plants (Jia et al., 2018). In a review of over 613 top-down effect studies in marine ecosystems, Poore et al. (2012) discovered that while top-down effects were generally strong in intertidal and coral reef systems, they were not significant in salt marshes. However, He and Silliman (2016) argued that the sample size for salt marsh ecosystems used for the analyses by Poore et al. (2012) was too small for the study's results to be reliable. They therefore carried out a follow-up meta-analysis to assess global variation in the strength of top-down effects in the coastal wetlands and found that consumers had a significant inhibitory effect on the survival, growth and reproduction of salt marsh plants (He and Silliman, 2016). Furthermore, the herbivory of both large-sized herbivores (e.g., cattle and sheep) and small-sized herbivores (e.g., insects) played an important role in plant population dynamics and community composition (Allan and Crawley, 2011; La Pierre et al., 2015; Katz, 2016; Borgstrom et al., 2017). Therefore, in the study of salt marsh and, more generally, plant ecology, top-down effects cannot be ignored.

Coastal areas cover only $4 \%$ of the world's land area, but they are home to a third of the world's population (UNEP, 2006). Coastal wetlands provide a multitude of ecosystem services for human beings, including coastline stabilization and storm protection, seafood, and tourism resources (Barbier et al., 2011). However, global change caused by human activities is driving the loss and degradation of coastal wetlands (Lotze et al., 2006). The studies considering both bottom-up and top-down effects on coastal wetland vegetation can provide vital reference information for how these imperiled ecosystems may be best protected and restored, and may continue to respond to climate change. However, studies on the top-down effect of coastal wetlands mainly focused on salt marshes in the American Continent (Silliman et al., 2005; Jefferies et al., 2006; Holdredge et al., 2009; Alberti et al., 2010; Daleo et al., 2011; Schultz et al., 2016), and only five studies from the entire Asian Continent were included in $\mathrm{He}$ and Silliman's (2016) meta-analysis of a total of 178 studies.

Furthermore, coastal wetlands are also experiencing a range of shifts in physical and chemical conditions due to human activities including nutrient enrichment, climate warming, and the spatial or temporal redistribution of precipitation, etc. (Deegan et al., 2012; Angelini et al., 2016). Herbivory may interact with these environmental changes with cascading impacts on both the vegetation biomass and structure (e.g. stem density, height, diameter). For example, hot, dry spells associated with drought can intensify snail grazing pressure in southeastern US salt marshes, causing the collapse of the dominant marsh cordgrass, Spartina alterniflora, in this region (Silliman et al., 2005). However, there are still few investigations on the impact of herbivory on the vegetation across seasons and years that vary in key environmental conditions, such as rainfall, in coastal wetlands (Angelini et al., 2018; Daleo et al., 2015).

The Yellow River Delta (YRD), formed by the intersection of the Yellow and Bohai Rivers, supports expansive intertidal wetlands in the warm temperate zone of eastern China. This dynamic ecosystem functions as a vital migration station in the East Asia-Australia water-bird migration route and as a key wintering habitat for birds. The YRD also supports a diversity of other ecosystem functions and services, including carbon sequestration, nutrient cycling, and nursery habitat provision for commercially and recreationally harvested fish and invertebrates, much like many other coastal wetlands around the world. The plant species' composition within YRD salt marshes is relatively simple, with regular zonation of largely mono-dominant plants. Phragmites australis (hereafter, Phragmites for brevity) is one of these dominant plants, covering approximately $5.39 \%$ of the YRD salt marsh area $\left(317 \mathrm{~km}^{2}\right.$ ) (Fan et al., 2020). Both marsh plant composition and growth (including Phragmites growth) are known to be highly sensitive to the changes in climate that are occurring in this region, which is particularly manifested by a decrease in annual precipitation, with considerably less precipitation occurring in the Spring but more rainfall in the Summer than was historically recorded (Chu et al., 2018; Han et al., 2018; Chu et al., 2019). Associated with intensifying spring droughts, salinization caused by less rainfall and higher evaporation is also occurring in these salt marshes (Guan et al., 2013).

Phragmites is one of the most important plant species structuring coastal wetlands of the YRD. Due to its spatial dominance and high provisioning of ecosystem functions and services, conserving Phragmites is a conservation priority in the region (Tang et al., 2006; Zhang et al., 2018a). Phragmites, a perennial grass and clonal plant, reproduces sexually by seed in Spring, and asexually by via vegetative expansion from Spring to Autumn. Each winter, this grass sheds its leaves. Most studies conducted thus far on Phragmites have focused on its responsiveness to gradients in salinity and the water table, factors that have been shown to influence its morphological and eco-physiological character, population dynamics and spatial distribution (Cui et al., 2006; Han et al., 2011; Guan et al., 2014; Chen et al., 2020). However, little is known about the role of consumers in controlling Phragmites in the salt marsh of the YRD. The herbivorous crab Helice tientsinensis is common and abundant in the salt marsh of YRD, and is known to consume multiple plant species such as Suaeda salsa, Salicornia europaea and Phragmites (He et al., 2015; Lan et al., 2020).

We therefore conducted a field experiment in the salt marsh of the YRD in which we manipulated herbivorous crab access to Phragmites (including the Ambient Crab, Procedural Cage Control and Crab Exclusion treatment). We ran the experiment over two years that spanned periods of significant variation of environmental stress: with relatively low environmental stress occurring in 2018 which experienced moderate rainfall and flooding frequency in Spring and lower soil porewater salinity but high environmental stress in 2019 which experienced reduced rainfall and flooding frequency in Spring, and higher salinity. This time-scale enabled us to investigate the effects of crab herbivory and environmental changes on multiple metrics of Phragmites' performance. We aimed to address the following scientific question: does the top-down effect of crabs amplify during drought years when plants may be additionally stressed by high salinity and reduced access to freshwater? This study advances our understanding of the top-down effect of herbivorous crabs on salt marsh vegetation structure, informing future efforts to conserve and restore Phragmites in the coastal wetland of the YRD.

\section{Materials and methods}

\subsection{Study site}

The study site was located in the salt marsh of the YRD in Shandong Province ( $37^{\circ} 44^{\prime} 5^{\prime \prime} \mathrm{N}, 119^{\circ} 12^{\prime} 56^{\prime \prime}$ E; Supporting information Fig. S1). 
The climate of this region is warm temperate with an annual average temperature of $11.7-12.6^{\circ} \mathrm{C}$; annual average rainfall of $530-630 \mathrm{~mm}$ with much of the rainfall occurring in July and August; annual average evaporation of 1750-2430 mm; and tidal flooding occurring through irregular semilunar and semidiurnal tides. The total discharge in the downstream of the Yellow River (measured in the Lijin County) were $5.54 \times 10^{8} \mathrm{~m}^{3}$ (specifically, 17th May-16th June: $6.30 \times 10^{7} \mathrm{~m}^{3}$ ) and $5.17 \times 10^{8} \mathrm{~m}^{3}$ (specifically, 17th May-16th June: $4.32 \times 10^{7}$ ) in 2018 and 2019 (Supporting information Fig. S2; data from the website of Yellow River Conservancy Commission of the Ministry of Water Resources, http://61.163.88.227:8006/hwsq.aspx). Within YRD salt marshes, the dominant plants exhibit regular zonation with Spartina alterniflora (an invasive species) being distributed along lower elevation salt marsh margins, and both S. salsa and Phragmites occurring through the intermediate and high marsh elevations. The Phragmites (Fig. S3 a) in the high marsh perform much worse than that from river sides or non-tidal wetlands (Chen et al., 2020). Helice tientsinensis (Shell length: $25.69 \pm 0.40 \mathrm{~mm}$; Shell breadth: $20.96 \pm 0.37 \mathrm{~mm} ; n=28$; Supporting information Fig. S3 b) alone dominates the infaunal crab community in the study site, and has been shown to regularly consume Phragmites (Lan et al., 2020).

\subsection{Field experiment}

In 16th May 2018, 15 plots (the plot size is $0.5 \times 0.5 \mathrm{~m}$ ) spaced $\sim 3 \mathrm{~m}$ apart were established in the Phragmites zone and randomly assigned one of three treatments: Ambient Crab, Procedural Cage Control and Crab Exclusion (Fig. S3 c-f; $n=5$ replicates per treatment). Crab Exclusion and Procedural Cage Control frames were rectangular with a length of $50 \mathrm{~cm}$, width of $50 \mathrm{~cm}$ and height of $150 \mathrm{~cm}$. A PVC frame without nylon fishing net attached was placed at each Ambient Crab treatment. For Crab Exclusion treatments, a nylon fishing net (with $1 \mathrm{~cm}$ meshes) was attached to the cage frame, and which was buried $40 \mathrm{~cm}$ underground to prevent crabs from entering. We also sprayed Permethrin pesticide (Qingdao Runsheng agrochemical Co. Ltd., China) one time to kill all crabs in the Crab Exclusion cages in May 2018 and 2019, because there were some small crabs (juvenile crabs, $<1 \mathrm{~cm}$ in carapace width) that had entered the cages in the spring. We only sprayed them on the soil surface, and avoided spraying them on the leaves of the plants. In addition, there was very little insect herbivory in the plots in May (personal observation), we anticipate it has limited effect on the result of our experiment. No crabs were in Crab Exclusion cages after the removal of crabs. The Procedural Cage Control treatment was identical to the Crab Exclusion Cage except that a $10 \mathrm{~cm}$ tall window was cut out of the mesh at the ground surface to enable crabs to freely enter and exit the cage.

Monthly, the salinity of the soil (at the depth of $10 \mathrm{~cm}$ and $20 \mathrm{~cm}$ ) was measured in situ by the electronic conductivity meter (ECTestr 11, Spectrum Technologies, Inc., USA) in each plot during June-September 2018, May-September 2019. The occurrence and the flooding frequency and duration, air/water temperature were also auto-recorded by water level recording sensor (CRS456, Campbell Scientific, USA) which logged a water depth each hour starting on April 16th 2018. The precipitation was recorded by a meteorological sensor (TE525 tipping bucket gauge, Texas Electronics, USA) on a half-hourly basis.

During the growing seasons (mid-May to mid-September) of 2018 and 2019, plant traits of Phragmites including the stem base diameter, stem height (recorded as the height of the tallest leaf), number of leaves per stem, leaf length and leaf breadth were measured for each stem in each plot every month. The proportion of the leaves of each stem exhibiting crab grazing damage were also recorded every month (except May and June 2018, the first months of the experiment). The inflorescences were measured in mid-September by counting the number of stems with inflorescences in the plots.

To prevent the disturbance of plants in the treatments, the biomass of Phragmites in each plot were estimated by regression equations (i.e., to predict the biomass of stem by using its height) at the end of the growing season (September) each year. First, stems for inclusion in our biomass regressions were collected outside the experimental plots, with 30 stems being collected for height-biomass measurements in each of the following three crab consumption categories: no crab herbivory, slight crab herbivory (the proportion of number of leaves per stem consumed was fewer than $2 / 3$ ) and heavy crab herbivory (the proportion of number of leaves per stem consumed was more than $2 / 3$ ). Then we dried the biomass in the oven with $65^{\circ} \mathrm{C}$ for $72 \mathrm{~h}$. Finally, the regression model of the biomass and the height were calculated. The regression equations were obtained as follows, Biomass = $0.160 \times$ Height $-8.383\left(R^{2}=0.80\right)$ for stems without crab herbivory; Biomass $=0.171 \times$ Height $-7.007\left(R^{2}=0.94\right)$ for stems with slight crab herbivory; while Biomass $=0.097 \times$ Height $-3.537\left(R^{2}=0.66\right)$ for stems with heavy crab herbivory. The predicted biomass of plots from the regression models have strongly positive correlation with the measured biomass of plots in this field site $\left(\mathrm{R}^{2}=0.98 ; n=21\right.$ plots $)$.

\subsection{Data analysis}

To minimize biases introduced by comparing different time periods in the analysis, we excluded the electronic conductivity in May 2019 and the proportion of leaves per stem consumed by crabs in May and June 2019 from the dataset.

Linear mixed-effect models were employed by $\operatorname{lmer}$ () function to reveal the impacts of crab treatment, month and year on the plant performances or salinity, because the mixed effect models can deal with the repeated measurement data. Mixed models explicitly account for the correlations between repeated measurements within each plots. Crab treatment, month and year were set as the fixed factors, and the plot was set as the random factor. Then, we calculated an index which indicated the direction of the interaction of crab treatment and year. The index formula was: the plant trait in "2019 Ambient Crab" treatment - "2018 Ambient Crab" treatment - "2019 Crab Exclusion" treatment + "2018 Crab Exclusion" treatment (Knol and VanderWeele, 2012). Positive index values are indicative of 'additive' interactions, meaning the two factors influenced a dependent variable, the effect was more than the sum of two factors' influence alone. Negative index values indicate sub-additive interactions, meaning the effect was less than the sum of two factors' influence alone.

Multiple comparisons were also conducted using the ls.means() function to compare means of different treatments, and $P$-value was corrected with the Benjamini and Hochberg (1995) ("BH") correction method by the function p.adjust(). All data were showed as mean \pm $\mathrm{SE}$ in the text. We performed statistical analyses and drew the figures using packages "lmerTest" and "ggplot2" respectively in R i386 3.4.2.

\section{Results}

\subsection{Changes of environmental stress from 2018 to 2019}

The salinity of the marsh soil, at both $10 \mathrm{~cm}$ and $20 \mathrm{~cm}$ depths, sampled during 4 months (June-September) in 2018 and 5 month in 2019 (May-September). The salinity at $10 \mathrm{~cm}(7.85 \pm 0.02 \mathrm{mS} / \mathrm{cm}$ vs. $6.42 \pm 0.02 \mathrm{mS} / \mathrm{cm}$; t-value $=-11.32$, P-value $<0.001)$ and $20 \mathrm{~cm}$ $(8.47 \pm 0.02$ vs. $6.85 \pm 0.02 \mathrm{mS} / \mathrm{cm}$; t-value $=-8.63$, Pvalue $<0.001$ ) were $22 \%$ and $23 \%$ higher in 2019 than 2018 (Tables S1-S2, Fig. 1 and Fig. S4, and the multiple comparisons of all the models in this paper were shown in the Supplementary Interactive Plot Data). The temperature between mid-April and mid-May of 2019 $\left(17.8 \pm 0.2{ }^{\circ} \mathrm{C}\right)$ and between mid-July and mid-August $\left(29.1 \pm 0.2^{\circ} \mathrm{C}\right)$ were both lower than the corresponding time periods in 2018 (midApril through mid-May: $18.6 \pm 0.2^{\circ} \mathrm{C}, P$-value $=0.01$; and mid-July through mid-August: $30.7 \pm 0.2{ }^{\circ} \mathrm{C}$, P-value $<0.001$; Fig. S5).

The temporal distribution of precipitation in 2019 was different from 2018 (Fig. 2). While the cumulative rainfall from March to May 


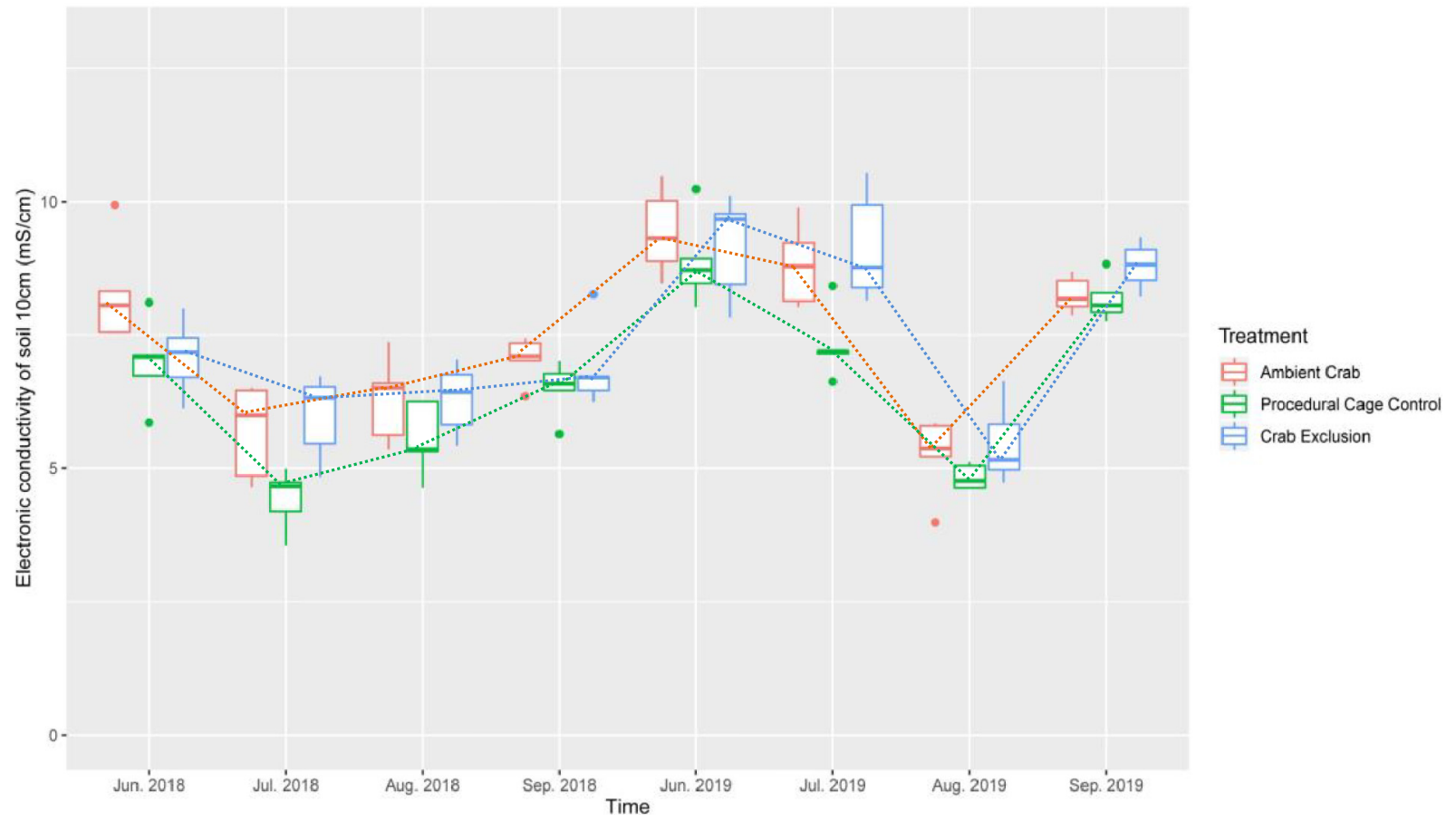

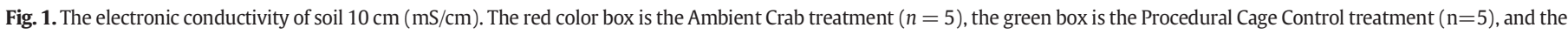

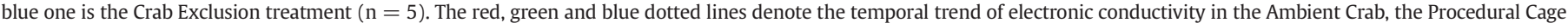
Control, and the Crab Exclusion treatment respectively.

(Spring) in 2018 (136.5 mm) was nearly four-times higher than that recorded in 2019 (32.7 mm), the opposite trend occurred mid-June to August (Summer) such that cumulative rainfall in 2018 (276 mm) was only a little more than half that which fell in 2019 (502 mm). The flooding frequency and total flood duration recorded at our field site during early growth season (5.17-6.16) in 2019 (5 times; 28 h) was fewer than 2018 (flood frequency: 8 times; flood duration: 93.5 h) (Fig. 3).

\subsection{Degree of crab consumption}

The result showed that the Crab Exclusion treatment was significantly reduced the proportion of number of leaves per stem consumed by crabs (Fig. 4 ). While $62.1 \pm 1.5 \%$ and $53.1 \pm 1.2 \%$ of leaves per stem exhibited some degree of crab damage in the Ambient Crab and Procedural Cage Control plots, respectively, only $4.8 \pm 0.4 \%$ of stems exhibited any evidence of grazing in the Crab Exclusion plots. Thus, the Crab

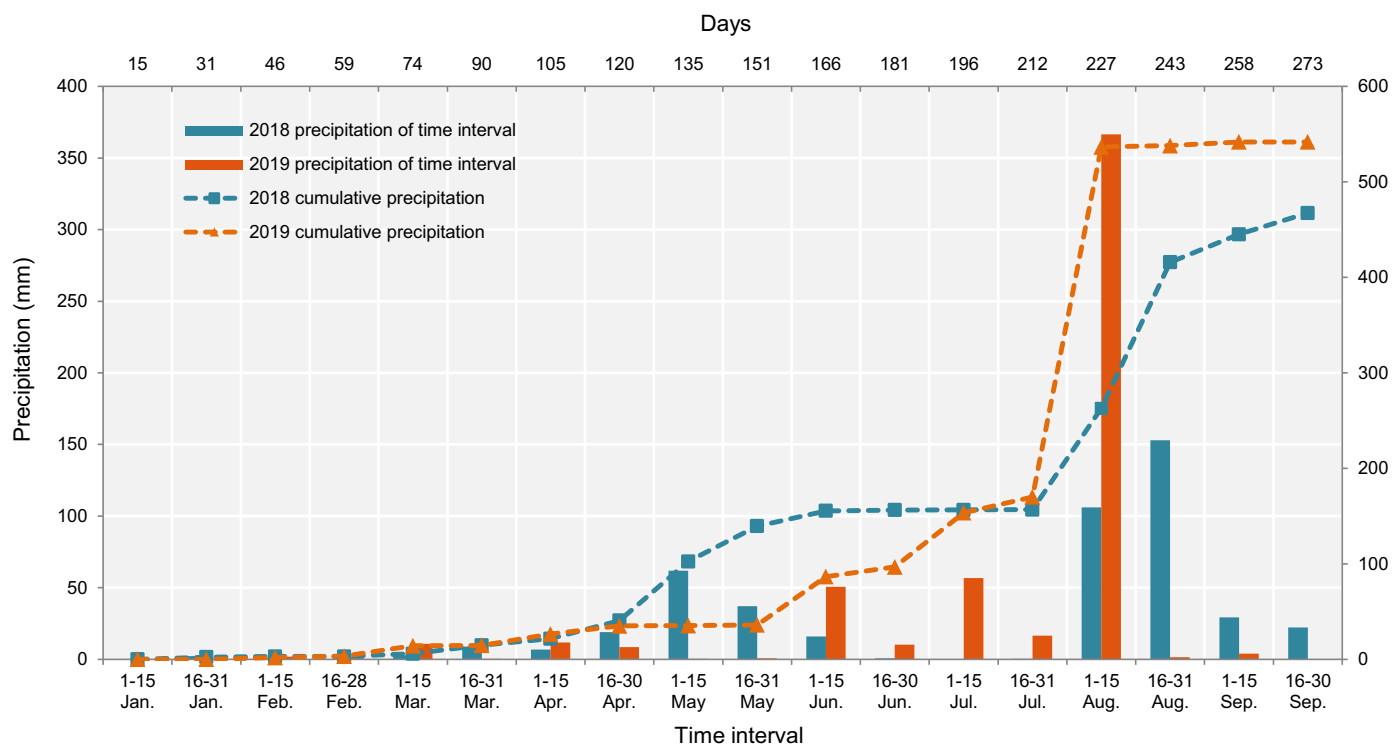

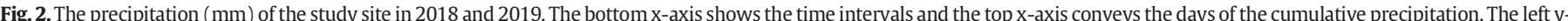

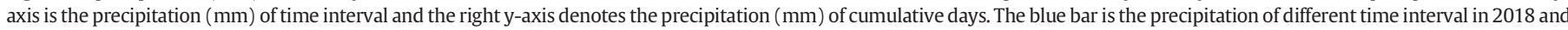

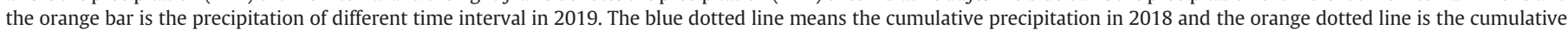
precipitation in 2019. 


\section{(a) Flood frequency}

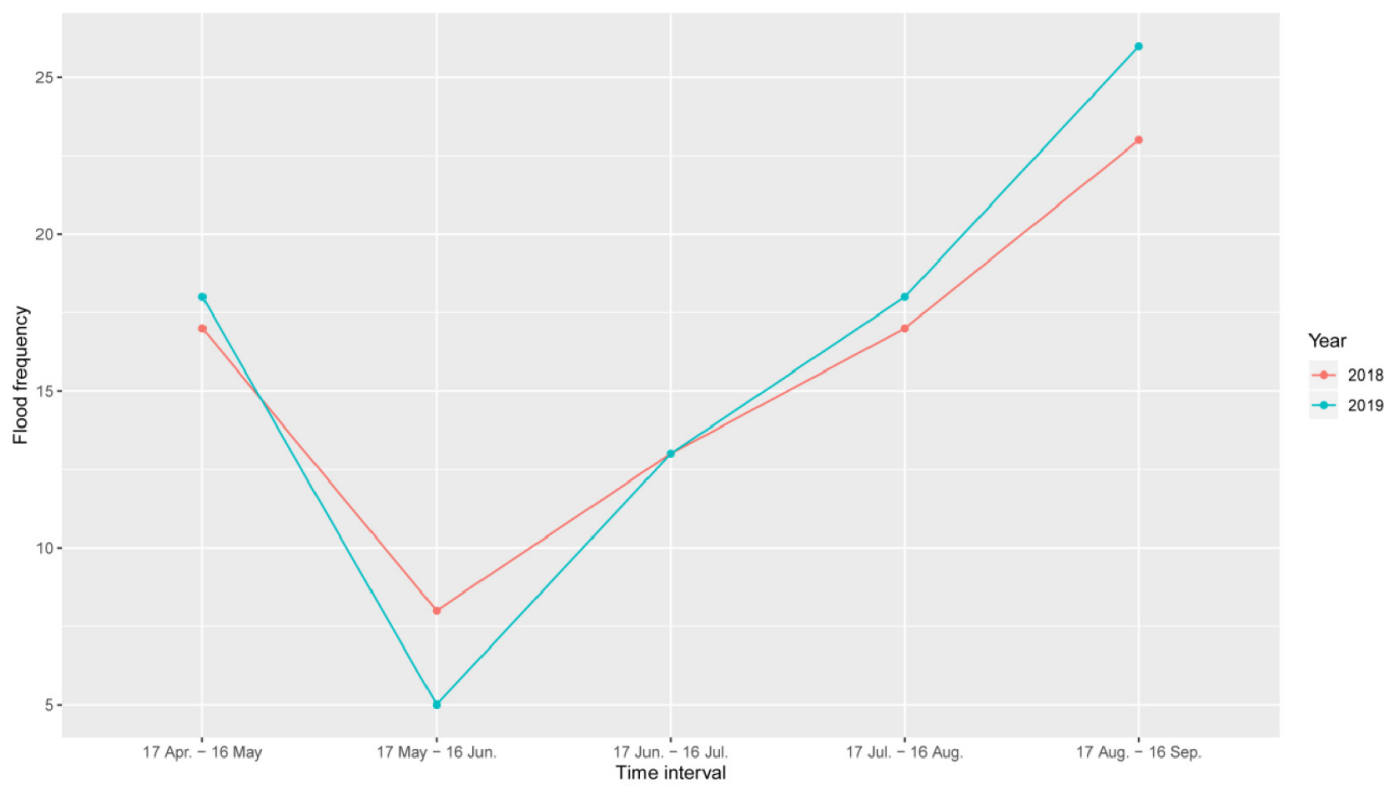

(b) Total flood duration

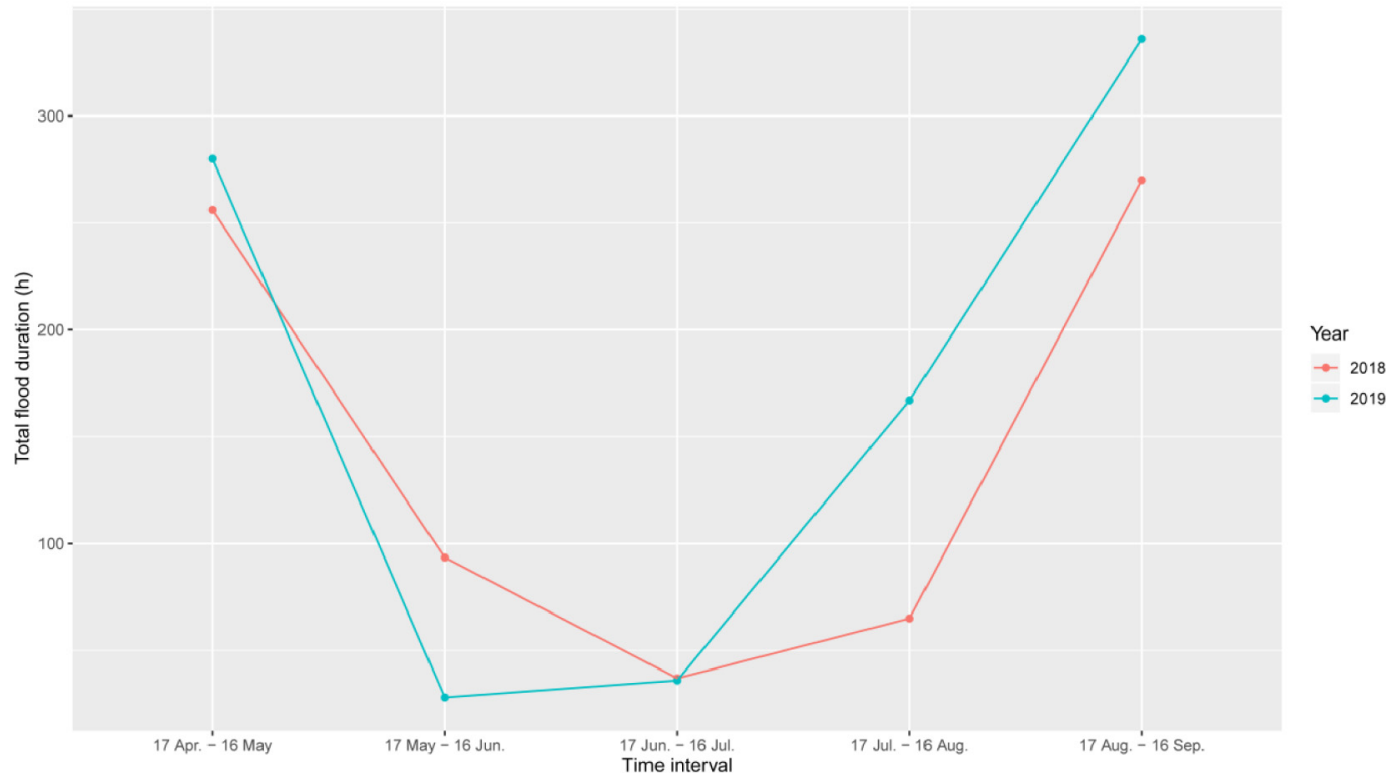

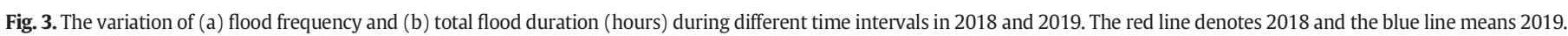

Exclusion treatment successfully reduced crab consumptive impacts on Phragmites, although crabs outside the cage climbed up the nets to eat some leaves from Phragmites inside the cage. In addition, the proportion of number of leaves per stem consumed by crabs in the Ambient Crab plots was significantly higher in Sep. 2019 than Sep. 2018 (2018: $56.3 \pm 3.3 \%$ vs. $2019: 73.4 \pm 5.7 \%$; -value $=-3.05, P$-value $=0.003)$.

\subsection{The effect of crab treatment, month and year on plant performances}

Given that we found no significant differences in any plant performance metric between Ambient Crab plots and Procedural Cage Control plots, we hereafter reported only differences between Crab Exclusion and Ambient Crab plots.

\subsubsection{Biomass}

Crab treatment (numDF $=2$, denDF $=12, \mathrm{~F}=12.49, P$-value $=$ 0.001 ), year $($ numDF $=1$, denDF $=12, F=46.10$, P-value $<0.001)$, and the interaction of crab treatment and year (numDF $=2$, denDF $=$ $12, \mathrm{~F}=8.52$, P-value $=0.005$ ) significantly influenced the biomass (unit: g) of Phragmites (Table 1). Phragmites' biomass was largely increased by the Crab Exclusion treatment in both 2018 and 2019. There was a sub-additive interaction between the crab herbivory and year on Phragmites' biomass (Table 2). While Phragmites biomass was 


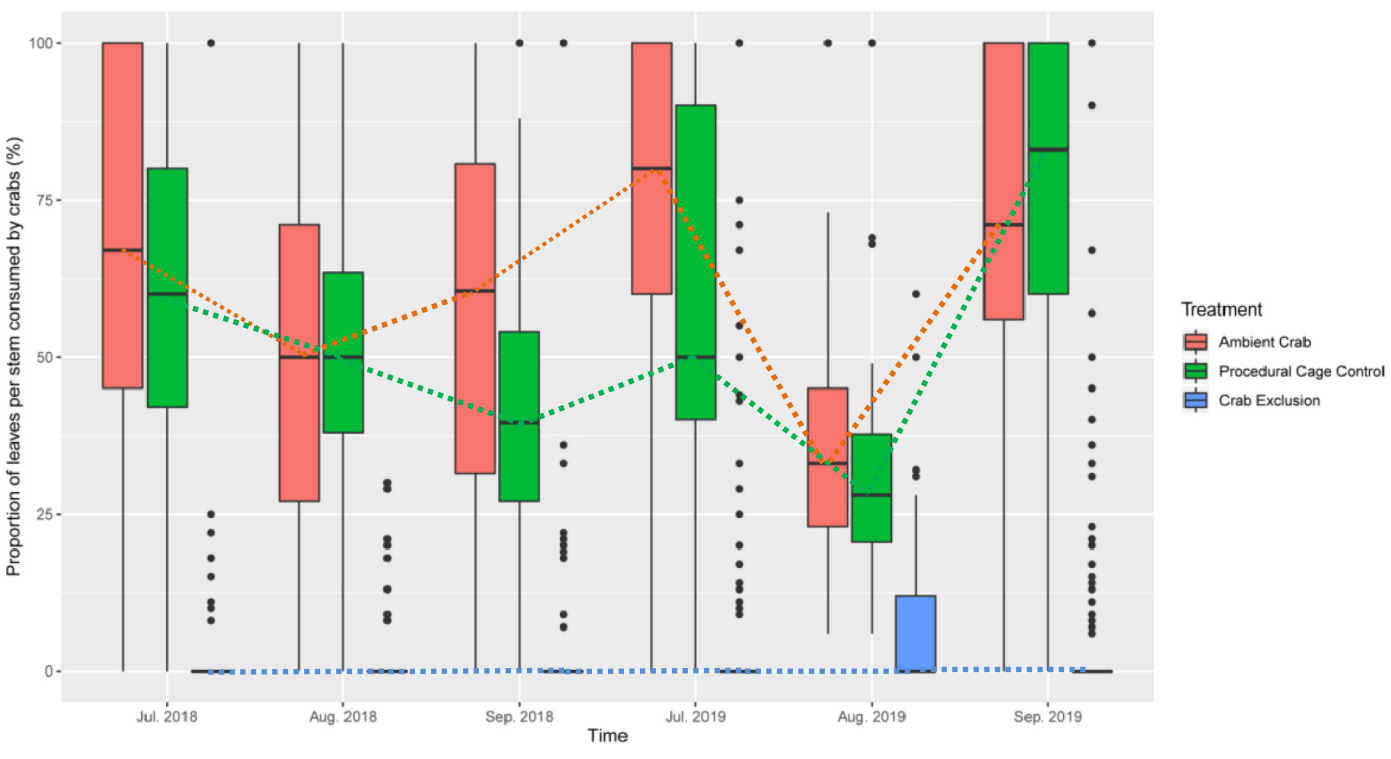

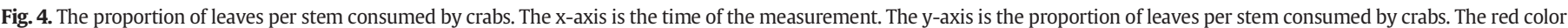

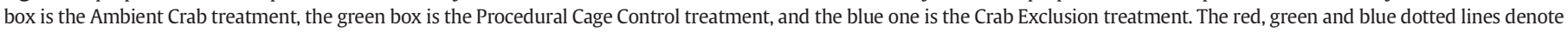
the temporal trend of electronic conductivity in the Ambient Crab, the Procedural Cage Control, and the Crab Exclusion treatment respectively.

similarly high in 2018 and 2019 for Crab Exclusion plots (164.50 \pm $19.13 \mathrm{~g}$ vs. $153.44 \pm 19.18 \mathrm{~g}$, $\mathrm{t}$-value $=0.67, P$-value $=0.54$ ), it was reduced by more than $40 \%$ in 2018 (93.83 $\pm 17.34 \mathrm{~g})$ and by $90 \%$ in 2019 $(14.91 \pm 1.60 \mathrm{~g})$ for Ambient Crab plots exposed to crab herbivory (Fig. 5a, t-value $=4.77, P$-value $<0.001$ ).

\subsubsection{Stem density}

Crab treatment numDF $=2$, denDF $=12, \mathrm{~F}=11.25, P$-value $=$ 0.002 ), month (numDF $=4$, denDF $=108, F=21.37, P$ value $<0.001$ ), year (numDF $=1$, denDF $=108, F=21.48, P$ value $<0.001)$, the sub-additive interaction of crab treatment and year $($ numDF $=2$, denDF $=108, F=72.81$, P-value $<0.001$; Table 2 ), and the interaction of month and year $($ numDF $=4$, denDF $=108$; $\mathrm{F}=8.49, P$-value $<0.001)$ significantly affected the number of Phragmites stems (Table 3, Fig. 5b).

Phragmites stem density more than doubled in Crab Exclusion plots (22.2 \pm 1.3 stems per plot) compared to Ambient Crab plots (9.6 \pm 1.0 stems per plot, $\mathrm{t}$-value $=-4.49, P$-value $=0.002)$. Across both treatments, the number of stems was significantly greater in 2018 than 2019 ( $16.1 \pm 0.9$ vs. $13.2 \pm 1.2$, respectively; $\mathrm{t}$-value $=4.63, P$ -

Table 1

Linear mixed-effects model predicting influences of the crab treatment ( $\mathrm{Crab}$ ) and year on the above-ground biomass of Phragmites australis.

\begin{tabular}{|c|c|c|c|c|c|c|}
\hline Effects & Sum square & Mean square & Num Df & Den Df & F-value & P-value \\
\hline \multicolumn{7}{|c|}{ Fixed effects } \\
\hline Crab & 17,057 & 8528 & 2 & 12 & 12.49 & $0.001^{* *}$ \\
\hline Year & 31,470 & 31,470 & 1 & 12 & 46.10 & $<0.001^{* * *}$ \\
\hline Crab: year & 11,630 & 5815 & 2 & 12 & 8.52 & $0.005^{* *}$ \\
\hline Effects & Npar & LogLik & AIC & LRT & Df & P-value \\
\hline \multicolumn{7}{|c|}{ Random effect } \\
\hline$<$ None $>$ & 8 & -124.36 & 264.72 & & & \\
\hline (1|plot) & 7 & -126.39 & 266.77 & 4.04 & 1 & $0.044^{*}$ \\
\hline
\end{tabular}

Note: Crab and year were considered fixed factors; plot was treated as random factors. Npar: number of model parameters; LogLik: the log-likelihood for the model; AIC: the AIC for the model evaluated as $-2 \times(\log L i k-$ Npar $)$, and smaller is better; LRT: the likelihood ratio test statistic. ${ }^{\text {**** }}$ denotes P-value $<0.001$; ${ }^{\text {***' }}$ means $P$-value $<0.01$; $^{\text {'*' }}$ indicates P-value $<0.05$. value $<0.001)$. For Ambient Crab plots, the number of stems was also more than 2-times higher in 2018 than 2019 (13.7 \pm 1.5 vs. $5.4 \pm 0.3$; $\mathrm{t}$-value $=7.66$, P-value $<0.001)$, while for Crab Exclusion plots, the number of stems was fewer in 2018 than 2019 (18.3 \pm 1.6 vs. $26.0 \pm$ 1.6; t-value $=-7.17$, P-value $<0.001$ ).

Furthermore, the crab treatment and year influenced the population dynamics. There was no significant difference of the number of stems of Ambient Crab plots in May between 2018 and 2019 ( $7.6 \pm 0.5$ stems vs. $5.2 \pm 0.7$ stems; $\mathrm{t}$-value $=0.99, P$-value $=0.41)$, however, the stem density of Ambient Crab plots in 2019 was fewer than 2018 since June $(11.8 \pm 1.6$ stems vs. $5.8 \pm 0.2$ stems; $\mathrm{t}$-value $=2.48, P$-value $=$ 0.029). On the contrary, the stem numbers in Crab Exclusion plots in May-July of 2019 was more than 2018 (May: t-value $=-6.37$, $P$-value $<0.001$; June: $\mathrm{t}$-value $=-4.38$, P-value $<0.001$; July:

Table 2

The directions of the interactive effect of crab treatment and year on the plant performances of Phragmites australis.

\begin{tabular}{|c|c|c|c|c|c|}
\hline \multirow[t]{2}{*}{ Plant traits } & \multirow[t]{2}{*}{ Year } & \multicolumn{2}{|l|}{ Crab treatment } & \multirow{2}{*}{\multicolumn{2}{|c|}{$\begin{array}{l}\text { Direction of the } \\
\text { interaction of crab } \\
\text { treatment and year }\end{array}$}} \\
\hline & & Crab exclusion & Ambient crab & & \\
\hline \multirow[t]{2}{*}{ Biomass (g) } & 2018 & 164.5 & 93.83 & -67.86 & Sub-additive \\
\hline & 2019 & 153.44 & 14.91 & & \\
\hline \multirow[t]{2}{*}{ Density } & 2018 & 18.28 & 13.72 & -16.04 & Sub-additive \\
\hline & 2019 & 26.04 & 5.44 & & \\
\hline \multirow[t]{2}{*}{ Height $(\mathrm{cm})$} & 2018 & 72.14 & 67.12 & -16.69 & Sub-additive \\
\hline & 2019 & 70.77 & 49.06 & & \\
\hline \multirow[t]{2}{*}{ Diameter (mm) } & 2018 & 4.39 & 4.74 & -0.14 & Sub-additive \\
\hline & 2019 & 4.05 & 4.26 & & \\
\hline \multirow[t]{2}{*}{ Number of leaves } & 2018 & 8.01 & 6.33 & -1.16 & Sub-additive \\
\hline & 2019 & 6.99 & 4.15 & & \\
\hline \multirow[t]{2}{*}{ Leaf length $(\mathrm{cm})$} & 2018 & 17.02 & 16.13 & -5.1 & Sub-additive \\
\hline & 2019 & 17.46 & 11.47 & & \\
\hline \multirow[t]{2}{*}{ Leaf breadth $(\mathrm{cm})$} & 2018 & 1.88 & 1.98 & -0.43 & Sub-additive \\
\hline & 2019 & 1.98 & 1.65 & & \\
\hline \multirow[t]{2}{*}{ inflorescences (\%) } & 2018 & 32.73 & 2.42 & 27.23 & Additive \\
\hline & 2019 & 3.08 & 0 & & \\
\hline
\end{tabular}

Note: The calculation (direction of the interaction of crab treatment and year) was: "2018 Crab Exclusion" + "2019 Ambient Crab" - "2018 Ambient Crab" - "2019 Crab Exclusion". If the value was positive, the direction was additive; and if the value was negative, the direction was sub-additive. 
(a) Above-ground biomass

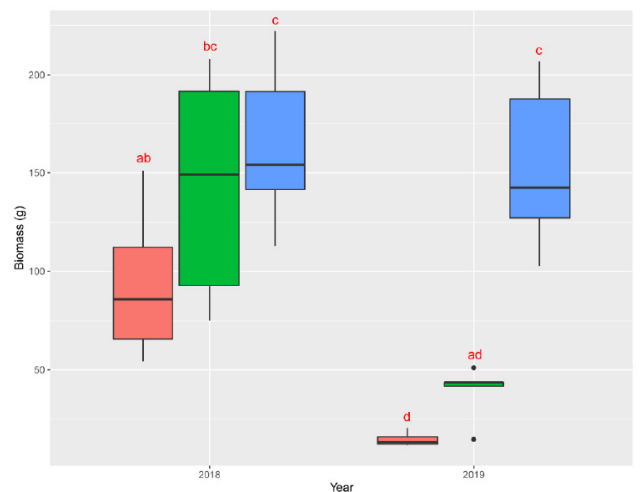

(c) Height

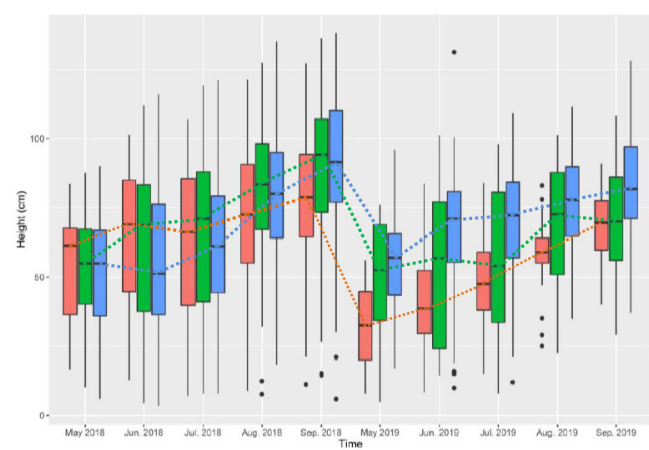

(e) Proportion of stems with inflorescences

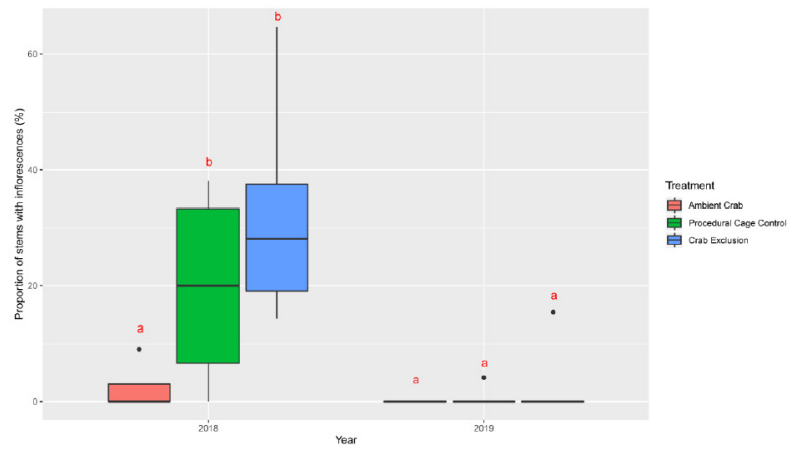

(b) Number of stems

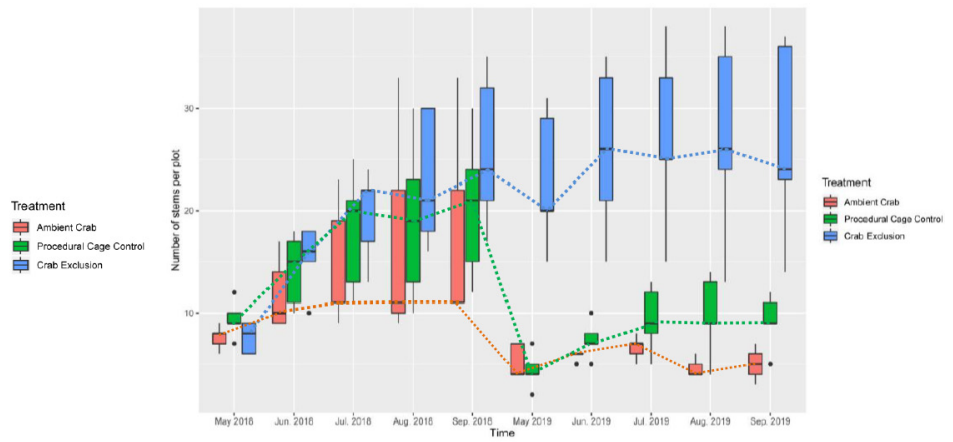

(d) Number of leaves

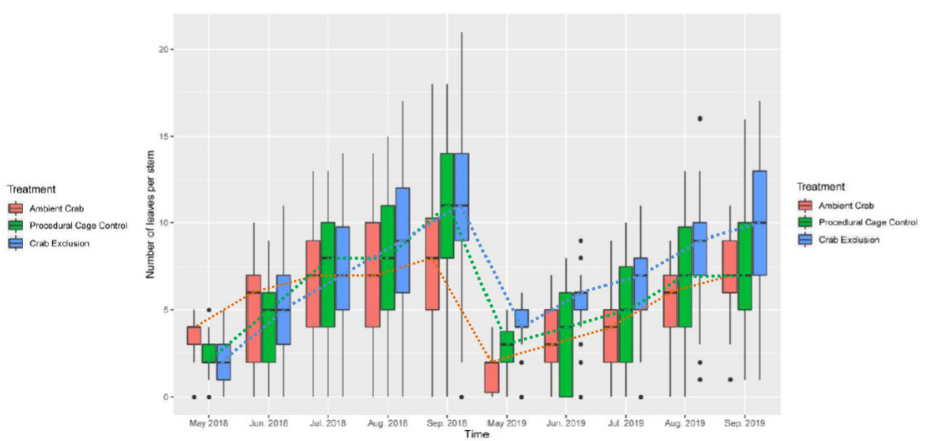

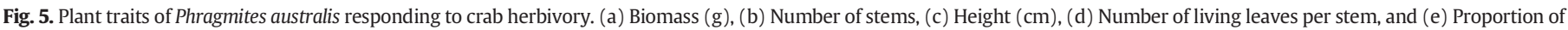

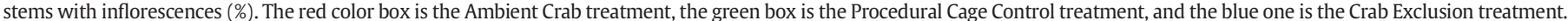

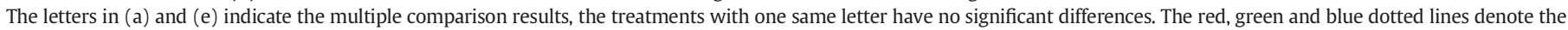
temporal trend of electronic conductivity in the Ambient Crab, the Procedural Cage Control, and the Crab Exclusion treatment respectively.

$\mathrm{t}$-value $=-3.14$, P-value $=0.005)$, but the stem numbers of Crab Exclusion plots in August and September 2019 was not significantly different from 2018 (August: $\mathrm{t}$-value $=-1.74, P$-value $=0.13$; September: $\mathrm{t}$-value $=-0.41$, P-value $=0.74)$. Thus, Ambient Crab plots kept in low stem density but Crab Exclusion plots kept in high stem density from May to September in 2019.

\subsubsection{Height}

Crab treatment $($ numDF $=2$, denDF $=12, \mathrm{~F}=4.46 ; P$-value $=$ 0.01 ), month (numDF $=4$, denDF $=2153 ; \mathrm{F}=88.93 ; \mathrm{P}$ value $<0.001$ ), year $($ numDF $=1$, denDF $=2159 ; \mathrm{F}=43.49 ; P$ value $<0.001$ ), as well as the sub-additive interaction of crab treatment and year $($ numDF $=2$, denDF $=2158, \mathrm{~F}=28.76$; $P$-value $<0.001)$ significantly affected the plant height (unit: $\mathrm{cm}$ ) of Phragmites (Table 2 and Table S3). The interaction of the crab treatment, month and year also significantly impacted the plant height (numDF $=8$, denDF $=2151$; $\mathrm{F}=2.01 ; P$-value $=0.04)$.

The plant height of Ambient Crab and Crab Exclusion plots was significantly different $(62.0 \pm 2.8 \mathrm{~cm}$ vs. $71.3 \pm 2.1 \mathrm{~cm}$, t-value $=-3.60$, $P$-value $=0.003$; Fig. 5c). The plant height in 2018 was higher than 2019 (70.5 $\pm 0.8 \mathrm{~cm}$ vs. $65.9 \pm 0.7 \mathrm{~cm} ; \mathrm{t}$-value $=6.59, P$ value $<0.001$ ). For Ambient Crab plots, the plant height from May to August but not September in 2018 was significantly higher than 2019. For Crab Exclusion plots, the plant height from May to July in 2018 was significantly higher than 2019, however, the plant height in August and September in 2018 was not significantly different from 2019.

\subsubsection{Diameter}

The crab treatment had no significant effect on the diameter (unit: $\mathrm{mm}$ ) of Phragmites (numDF $=2$, denDF $=12.1, \mathrm{~F}=0.43, P$-value $=$ 0.66 ), but month (numDF $=4$, denDF $=2151, \mathrm{~F}=17.46$, 
Table 3

Linear mixed-effects model predicting influences of the crab treatment (crab), growth stage and year on the stem numbers of Phragmites australis.

\begin{tabular}{|c|c|c|c|c|c|c|}
\hline Effects & Sum square & Mean square & Num Df & Den Df & F-value & P-value \\
\hline \multicolumn{7}{|l|}{ Fixed effects } \\
\hline Crab & 329 & 164.5 & 2 & 12 & 11.25 & $0.002^{* *}$ \\
\hline Growth stage & 1249 & 312.2 & 4 & 108 & 21.37 & $<0.001^{* * *}$ \\
\hline Year & 313 & 313.9 & 1 & 108 & 21.48 & $<0.001^{* * *}$ \\
\hline Crab: growth stage & 116 & 14.6 & 8 & 108 & 1.00 & 0.440 \\
\hline Crab: year & 2128 & 1064 & 2 & 108 & 72.81 & $<0.001^{* * *}$ \\
\hline Growth stage: year & 496 & 124.1 & 4 & 108 & 8.49 & $<0.001^{* * *}$ \\
\hline Crab: growth stage: year & 60 & 7.5 & 8 & 108 & 0.52 & 0.843 \\
\hline Effects & Npar & LogLik & AIC & LRT & Df & P-value \\
\hline \multicolumn{7}{|l|}{ Random effect } \\
\hline$<$ None $>$ & 32 & -370.93 & 805.86 & & & \\
\hline (1|plot) & 31 & -403.86 & 869.73 & 65.87 & 1 & $<0.001^{* * *}$ \\
\hline
\end{tabular}

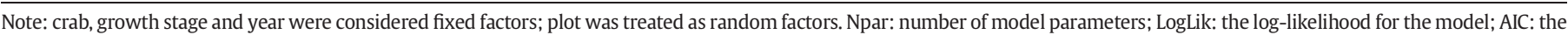
AIC for the model evaluated as $-2 \times\left(\operatorname{logLik}-\right.$ Npar), and smaller is better; LRT: the likelihood ratio test statistic. ${ }^{* * * * *}$ denotes P-value $<0.001$; “**' means P-value $<0.01$.

P-value $<0.001)$, year $($ numDF $=1$, denDF $=2152, \mathrm{~F}=64.29, P-$ value $<0.001$ ), the interaction of crab treatment and month (numDF $=$ 8 , denDF $=2151, \mathrm{~F}=3.44$, P-value $<0.001$; Table S4), the sub-additive interaction of crab treatment and year $(\mathrm{numDF}=2$, denDF $=2152$, $\mathrm{F}=16.03, P$-value $<0.001$; Table 2 ), the interaction of month and year $($ numDF $=4$, denDF $=2151, \mathrm{~F}=12.68, P$-value $<0.001)$, and the interaction of crab, month and year all had significant effects on Phragmites' diameter (numDF $=8$, denDF $=2151, \mathrm{~F}=2.82$, Pvalue $=0.004$; Fig. S6 a).

\subsubsection{Leaves}

Crab treatment (numDF $=2$, denDF $=12.28, F=19.48$, $P$-value $<0.001$ ), month (numDF $=4$, denDF $=1827, \mathrm{~F}=185.44, \mathrm{P}-$ value $<0.001$ ), year (numDF $=1$, denDF $=1835, \mathrm{~F}=39.09, P$ value $<0.001$ ), the interaction of crab treatment and month (numDF $=$ 8 , denDF $=1827, \mathrm{~F}=2.73, P$-value $=0.005$ ), the sub-additive interaction of crab treatment and year $(\mathrm{numDF}=2$, denDF $=1834, \mathrm{~F}=12.38$, P-value $<0.001$; Table 2 ), the interaction of month and year (numDF $=$ 2 , denDF $=1825, \mathrm{~F}=5.02, P$-value $<0.001$ ), and the interaction of crab, month and year $($ numDF $=4, \operatorname{denDF}=1825, \mathrm{~F}=2.26, P$-value $=$ 0.007 ) were significantly influenced the number of leaves per stem (Table S5 and Fig. 5d). There were significant differences of the number of leaves per stem between Ambient Crab and Crab Exclusion plots $(7.4 \pm 0.1$; -value $=-6.03, P$-value $<0.001)$. The number of leaves per stem was greater in 2018 than 2019 (7.2 \pm 0.1 vs. $6.3 \pm 0.1$; tvalue $=6.25$, P-value $<0.001)$. The numbers of leaves per stem of Ambient Crab plots in 2018 (6.3 \pm 0.2$)$ were more than Ambient Crab plots $(4.2 \pm 0.2)$ in 2019 ( $\mathrm{t}$-value $=5.22$, P-value $<0.001)$. However, the number of leaves per stem of Crab Exclusion in 2018 (8.0 \pm 0.2$)$ was not significantly different from Crab Exclusion in 2019 (7.0 \pm 0.1 ; tvalue $=0.08$, P-value $=0.94$ )

All dependent variables except crab treatment were all significant drivers of leaf length (unit: cm; Table S6 and Fig. S6 b), and the interaction of the crab and year was sub-additive (Table 2). In addition, Year (numDF $=1$, denDF $=2152, F=25.37$, P-value $<0.001$ ), the subadditive interaction of crab treatment and year ( numDF $=2$, denDF $=$ $2152, \mathrm{~F}=14.02$, P-value $<0.001$; Table 2 ), the interaction of month and year $($ numDF $=4$, denDF $=2150, F=6.72$, P-value $<0.001$; Table S7 and Fig. S6 c) significantly affected the leaf breadth (unit: $\mathrm{cm}$ ).

\subsubsection{Inflorescences}

Crab treatment (numDF $=2$, denDF $=12, \mathrm{~F}=6.19$, P-value $=$ 0.014 ), year (numDF $=1$, denDF $=12, \mathrm{~F}=30.60$, P-value $<0.001$ ), the additive interaction of crab treatment and year (numDF $=2$, denDF $=12, \mathrm{~F}=0.037, \mathrm{P}$-value $=0.04$; Table 2 ) had significant impacts on the proportion of stems with inflorescences (Table S8 and Fig. 5e). The proportion of stems with inflorescences in Ambient Crab (0.2 \pm $0.1 \%)$ was less than Crab Exclusion $(1.4 \pm 0.1 \%$; t-value $=-3.50$,
P-value $=0.010)$. The percent of stems with inflorescences in 2018 $(1.7 \pm 0.1 \%)$ was greater than $2019(0.1 \pm 0.0 \%$; $t$-value $=5.35$, Pvalue $<0.001)$. For Ambient Crab plots, the inflorescences in 2018 $(0.3 \pm 0.1 \%)$ were not significant different with $2019(0$; $\mathrm{t}$-value $=$ 0.95 , P-value $=0.49$ ), but for Crab Exclusion plot, the inflorescences in $2018(2.8 \pm 0.2 \%)$ were significantly more than $2019(0.1 \pm 0.0 \%$; $\mathrm{t}$-value $=5.09$, P-value $=0.001)$. In 2018, the inflorescences in Crab Exclusion plots were more than Ambient Crab (t-value $=-4.56$, Pvalue $<0.001$ ); however in 2019, the inflorescences in Crab Exclusion plots were not significantly different from Ambient Crab ( $\mathrm{t}$-value $=$ -0.73 , P-value $=0.60$ ).

\section{Discussion}

Our study provides compelling evidence that the herbivorous crab, Helice, can reduce Phragmites' biomass by $40-90 \%$, suppress its reproductive capacity and transform its stand structure by damaging leaves and thinning stems, in a salt marsh representative of those present throughout the YRD. These findings complement and significantly expand upon prior studies, which have shown that crab herbivory could negatively affect the plant traits (i.e., height, leaf length, leaf numbers) of juvenile (i.e., early growth stage) Phragmites clones (Zhang et al., 2018b). Helice can consume Phragmites leaves (Lan et al., 2020), as well as regulate the growth and distribution of the dominant species S. salsa and the rare species Salicornia europaea in YRD salt marshes (He et al., 2015). Contrary to the above studies which were conducted over relatively short time scales, our study ran for nearly two years and significantly expands upon this body of research by revealing that this crab herbivore is exerting significant top-down control of the Phragmites, a spatially dominant species in this system, and that their impacts are enhanced by Spring drought, an increasing manifestation of climate change in eastern Asia. Thus, our study deepens fundamental understanding of mechanisms controlling plant community structure and function in this coastal wetland and this valuable systems' sensitivity to climate change.

Furthermore, our findings also support studies from coastal wetlands in other regions around the world that have similarly shown that salt marshes are strongly regulated by consumers, such as fungalfarming snails and herbivorous crabs, (Silliman et al., 2005; Holdredge et al., 2009; Schultz et al., 2016). Herbivory by geese and crabs has also been shown to affect plant growth, reproduction and distribution in coastal wetlands in Canada and South America (Jefferies et al., 2006; Alberti et al., 2008; Alberti et al., 2010; Alberti et al., 2011; Daleo et al., 2011; Daleo et al., 2015). Thus, our study from the coastal wetland of east Asia provided new evidence supporting previous assertions that strong consumer control of salt marshes is globally pervasive and must therefore be widely considered in efforts to manage and conserve these valuable coastal wetlands (He and Silliman, 2016). 
Our results revealed fairly pronounced differences in environmental conditions in the YRD over the two years of this study. Across both years, less precipitation occurred in Spring relative to the Summer, seasonal precipitation differences that have been previously noted in other recent salt marsh field studies (e.g. He et al. (2017), Han et al. (2018) and Chu et al. (2019)). Moreover, the tidal inundation including the flood frequency and flood duration was reduced in the Spring of 2019 than Spring of 2018, and which made the Spring drought even more severe, and the salinity of the soil considerably higher in 2019 than in 2018.

Our results showed that the plant performances of Phragmites were considerably reduced from 2018 to 2019. This result suggests that spring drought, spring low temperatures and higher salinity in 2019 suppressed the fitness of Phragmites but only in plots where this dominant plant was also subjected to grazing pressure by Helice. The establishment of plants in the Spring is very important for controlling end-of-growing season plant yields, and crabs appear to interact nonadditively with Spring drought to control early-season growth. Chu et al. (2018) also found that less precipitation in the spring had a negative influence on the plant community (Phragmites was a dominant species) above-ground biomass at the end of the growth season in the seasonal rainfall waterlogged wetland of the YRD in 2012 and 2013. He et al. (2017) reported that Spring drought inhabited the S. salsa seedling establishment and led to the die-off of this common plant in salt marshes of the YRD. Although only seasonal drought occurred in these studies, it could have significantly negative effect on the vegetation, which suggested vegetation in tidal wetland was susceptive to drought even seasonal drought. Thus, freshwater availability is crucial for vegetation in the coastal wetland. Many tidal wetlands around the world are also experiencing reductions in precipitation and well as in riverine and groundwater inputs, enhancing coastal wetland plant vulnerability to salinization and water limitation (Osland et al., 2014; Cherry and Battaglia, 2019) and thus widely challenging efforts to conserve these systems.

On the other hand, the interaction of crab herbivory and year on the growth traits and clonal reproduction of Phragmites was sub-additive. For Ambient Crab plots, most of the plant performances were significantly inhibited from 2018 to 2019. However, for Crab Exclusion plots, the plant performances, except the number of stems, were not significantly different between 2018 and 2019, although the number of stems was higher in 2019 than 2018 in these treatments where crab grazing pressure was reduced. These results indicated that, without crab herbivory, the intensification of Spring drought that occurred from 2018 to 2019, did not correspond to significant reductions in these metrics of Phragmites performance (except inflorescences).

In the consumer stress model proposed by Silliman et al. (2013), it is hypothesized that consumer stress can interact additively or synergistically with physical stress. However, in our study, the interactive effects of consumer stress and physical stress on most metrics of Phragmites' performances (expect inflorescences, additive) were non-additive, meaning that the reduction in Phragmites' growth and clonal reproduction were less than one would expect from the sum of the independent effects of crab herbivory and Spring drought. One possible reason was that crab herbivory stress was the most limiting factor influencing the growth and clonal reproduction of Phragmites at our field site, and, thus, the impact of consumer stress generally overwhelmed the relatively smaller, less impactful effect of Spring drought in controlling Phragmites' performance. Where crab consumer pressure was mitigated in our exclusion cages, Phragmites recovered rapidly and sustained high productivity despite increasing physical stress due to drought in year 2 . In contrast, inflouresences may be more sensitive to environmental stress relative to the other plant traits, as crab herbivory and high environmental stress additively inhibited the production of these reproductive structures. Thus, this metric alone did support the He and Silliman consumer stress model. Thus, the agreement between our findings and the consumer stress model varies with the plant performance metrics considered. Looking ahead, we suggest that longer-term and larger spatial-scale studies are needed to better resolve the impact of potential fluctuations in both Helice population size and consumer impacts, as well as in Spring drought intensity and other environmental stressors on the fitness of Phragmites' and population dynamics.

Our experiment also revealed that Phragmites is highly vulnerable to crab herbivory but that the level of sensitivity varied across measured traits. Many plant functional traits, including the biomass, density, height, number of leaves and inflorescences, were reduced by crab herbivory. However, the diameter, leaf length and leaf breadth of Phragmites were not affected by crab treatment. Although crabs directly consumed the leaves, crab herbivory only had a negative effect on the number of leaves. On the other hand, the diameter, leaf length, leaf breadth and the inflorescences were reduced from 2018 to 2019, and it suggested that these traits may be more sensitive to environmental changes. Thus, not all plant traits of Phragmites were sensitive to the crab herbivory or environmental changes, and a variety of plant traits were suggested to be measured when investigating the impacts of the top-down effect or environmental changes.

Phragmites reproduces both sexually and asexually, and the reproductive traits included both the number of stems and inflorescences in our study. Exclusion of crabs increased the number of stems dramatically and the proportion of stems with inflorescences in 2018. Therefore, recruitment limitation due to crab herbivory may be an important cause of the degradation of the Phragmites vegetation in this coastal wetland. We predicted that if the Phragmites vegetation released from the consumer stress, they would potentially produce five- times more stems in only two years. This may be an effective way (such as increasing the avian predators) to recover the degraded the Phragmites vegetation in this salt marsh. For example, given that Helice is the main food source of the Red-crowned Crane (Grus japonensis), Larus spp., Sterna spp., Ardea spp. etc. (Li et al., 2014; He and Cui, 2015), efforts to rejuvenate these bird populations have the potential to mitigate crab herbivory of Phragmites.

There may be some possible limitations in this study. One is that water supply was not directly manipulated in the experiment, thus it is possible that some other factor caused the difference in plant performances between 2018 and 2019. However, it is very difficult to manipulate freshwater supply/salinity at this site and in intertidal marshes more generally (but see Angelini and Silliman (2012)), given the role of both precipitation and tidal exchange in controlling this key environmental driver. Water supply showed markedly different temporal dynamics in 2018 versus 2019, providing us an opportunity to investigate in a correlative manner the effect of temporal variation of water supply on the plant-crab relationship. A second limitation to our study is that we continued the experimental manipulations first established in 2018 through 2019 and, because of this, we cannot resolve the degree to which the response of the plots to the drought in 2019 was influenced by the plots' months of conditioning to the crab treatments. To disentangle the relative importance of the drought conditions versus carry-over, 'legacy' treatment effects (which in the case of our study are manifested in Phragmites' increased growth in crab removal plots), it would have been ideal to initiate a second paired experiment beginning in 2019 with the same treatments. If treatment effect sizes were similar between the longer-term and single-season study, we would be able to conclude that the carry-over crab treatment effects were not important in mediating Phragmites' drought resilience. However, if we found that Phragmites was more, or less, resistant to the drought in the two-season versus single-season we would be able to resolve whether chronic crab herbivory conditions Phragmites to be more/ less resilient to drought events.

\section{Conclusion}

In summary, this study evaluated the importance of crab herbivory on the vegetation under the background of temporal environmental 
change in the salt marsh of the Yellow River Delta. Our results showed that crab exclusion increased the biomass, stem density, stem height, leave density, and proportion of stems with inflorescences of Phragmites. Moreover, the growth and reproduction of common reed in Ambient Crab and Procedural Cage Control was significantly reduced in 2019 comparing to 2018, which may be due to both crab herbivory and environmental stress such as higher salinity, less precipitation, flooding frequency and duration in the early growth season (April, May and June). However, the biomass and stem density of common reed in Crab Exclusion plots did not change at the end of the growing season from 2018 to 2019. It suggested that, without crab herbivory, Phragmites had the potential to better resist the negative effects of reduced rainfall and waterlog in the Spring, and the slight rise of salinity. Therefore, crab herbivory along with environmental stress degraded Phragmites vegetation in the salt marsh of the YRD at a two-year scale. It may help us to better understand the mechanisms of vegetation degradation in the coastal wetland and provide knowledge basis for the restoration of the vegetation in the coastal wetland under the background of global change.

\section{CRediT authorship contribution statement}

Liwen Zhang: Conceptualization, Methodology, Data curation, Visualization, Writing - original draft, Funding acquisition. Siqun Lan: Investigation, Data curation. Christine Angelini: Data curation, Writing - review \& editing. Huapeng Yi: Conceptualization, Investigation. Lianjun Zhao: Investigation. Lin Chen: Investigation. Guangxuan Han: Conceptualization, Supervision.

\section{Declaration of competing interest}

The authors declare that they have no known competing financial interests or personal relationships that could have appeared to influence the work reported in this paper.

\section{Acknowledgments}

This research has been funded by the National Natural Science Foundation of China (31971504), and the Youth Innovation Promotion Association, Chinese Academy of Sciences (2018247).

\section{Appendix A. Supplementary data}

Supplementary data to this article can be found online at https://doi. org/10.1016/j.scitotenv.2020.144254.

\section{References}

Alberti, J., Escapa, M., Iribarne, O., Silliman, B.R., Bertness, M., 2008. Crab herbivory regulates plant facilitative and competitive processes in Argentinean marshes. Ecology 89, 155-164.

Alberti, J., Casariego, A.M., Daleo, P., Fanjul, E., Silliman, B., Bertness, M., et al., 2010. Abiotic stress mediates top-down and bottom-up control in a Southwestern Atlantic salt marsh. Oecologia 163, 181-191.

Alberti, J., Cebrian, J., Casariego, A.M., Canepuccia, A., Escapa, M., Iribarne, O., 2011. Effects of nutrient enrichment and crab herbivory on a SW Atlantic salt marsh productivity. J. Exp. Mar. Biol. Ecol. 405, 99-104.

Allan, E., Crawley, M.J., 2011. Contrasting effects of insect and molluscan herbivores on plant diversity in a long-term field experiment. Ecol. Lett. 14, 1246-1253.

Angelini, C., Silliman, B.R., 2012. Patch size-dependent community recovery after massive disturbance. Ecology 93, 101-110.

Angelini, C., Griffin, J.N., van de Koppel, J., Lamers, L.P.M., Smolders, A.J.P., DerksenHooijberg, M., et al., 2016. A keystone mutualism underpins resilience of a coastal ecosystem to drought. Nat. Commun. 7.

Angelini, C., van Montfrans, S., Hensel, M.S., He, Q., Silliman, B.R., 2018. The importance of an underestimated grazer under climate change: how crab density, consumer competition, and physical stress affect salt marsh resilience. Oecologia 187, 205-217.

Barbier, E.B., Hacker, S.D., Kennedy, C., Koch, E.W., Stier, A.C., Silliman, B.R., 2011. The value of estuarine and coastal ecosystem services. Ecol. Monogr. 81, 169-193.

Benjamini, Y., Hochberg, Y., 1995. Controlling the false discovery rate - a practical and powerful approach to multiple testing. J. R. Stat. Soc. B 57, 289-300.
Bertness, M.D., 2007. Atlantic Shorelines: Natural History and Ecology. Princeton University Press, Princeton.

Borgstrom, P., Strengbom, J., Marini, L., Viketoft, M., Bommarco, R., 2017. Above- and belowground insect herbivory modifies the response of a grassland plant community to nitrogen eutrophication. Ecology 98, 545-554.

Chalifour, B., Hoogveld, J.R.H., Derksen-Hooijberg, M., Harris, K.L., Uruena, J.M., Sawyer, W.G., et al., 2019. Drought alters the spatial distribution, grazing patterns, and radula morphology of a fungal-farming salt marsh snail. Mar. Ecol. Prog. Ser. 620, 1-13.

Chen, L., Zhang, L.W., Liu, Z.T., Lu, F., Feng, G.H., Yan, K., et al., 2020. Physiological and ecological responses of hetan and chaotan Phragmites australis to salt stress. Acta Ecol. Sin. 40, 2090-2098.

Cherry, J.A., Battaglia, L.L., 2019. Tidal wetlands in a changing climate: introduction to a special feature. Wetlands 39, 1139-1144

Chu, X.J., Han, G.X., Xing, Q.H., Xia, J.Y., Sun, B.Y., Yu, J.B., et al., 2018. Dual effect of precipitation redistribution on net ecosystem $\mathrm{CO}_{2}$ exchange of a coastal wetland in the Yellow River Delta. Agric. For. Meteorol. 249, 286-296.

Chu, X.J., Han, G.X., Xing, Q.H., Xia, J.Y., Sun, B.Y., Li, X.G., et al., 2019. Changes in plant biomass induced by soil moisture variability drive interannual variation in the net ecosystem $\mathrm{CO}_{2}$ exchange over a reclaimed coastal wetland. Agric. For. Meteorol. 264, 138-148.

Cui, B.S., Zhao, X.S., Yang, Z.F., Tang, N., Tan, X.J., 2006. The response of reed community to the environment gradient of water depth in the Yellow River Delta. Acta Ecol. Sin. 26 1533-1541.

Daleo, P., Alberti, J., Iribarne, O., 2011. Crab herbivory regulates re-colonization of disturbed patches in a southwestern Atlantic salt marsh. Oikos 120, 842-847.

Daleo, P., Alberti, J., Bruschetti, C.M., Pascual, J., Iribarne, O., Silliman, B.R., 2015. Physical stress modifies top-down and bottom-up forcing on plant growth and reproduction in a coastal ecosystem. Ecology 96, 2147-2156.

Deegan, L.A., Johnson, D.S., Warren, R.S., Peterson, B.J., Fleeger, J.W., Fagherazzi, S., et al., 2012. Coastal eutrophication as a driver of salt marsh loss. Nature 490, 388-392.

Fan, Y.B., Zhou, D.M., Ke, Y.H., Wang, Y.Z., Wang, Q.W., Zhang, L., 2020. Quantifying the correlated spatial distributions between tidal creeks and coastal wetland vegetation in the Yellow River Estuary. Wetlands. 40, 2701-2711.

Guan, B., Yu, J.B., Cao, D., Li, Y.Z., Han, G.X., Mao, P.L., 2013. The ecological restoration of heavily degraded saline wetland in the Yellow River Delta. Clean Soil Air Water 41, 690-696.

Guan, B., Li, Y.Z., Xia, J.B., Dong, H.F., Lu, Z.B., Yu, J.B., 2014. Ecological characteristics of Phragmites australis vegetation at different water table levels and their relation to environmental factors in the Yellow River Delta. Chin. J. Ecol. 33, 2633-2639.

Hairston, N.G., Smith, F.E., Slobodkin, L.B., 1960. Community structure, population control, and competition. Am. Nat. 94, 421-425.

Han, P., Wu, G., Wu, Y.Q., Xiang, J., Yu, L.J., 2011. Response of Phragmites australis morphostructure to the different habitats in the Yellow River Delta. Wetland Sci. 9, 185-190.

Han, G.X., Sun, B.Y., Chu, X.J., Xing, O.H., Song, W.M., Xia, J.Y., 2018. Precipitation events reduce soil respiration in a coastal wetland based on four-year continuous field measurements. Agric. For. Meteorol. 256, 292-303.

He, Q., Cui, B.S., 2015. Multiple mechanisms sustain a plant-animal facilitation on a coastal ecotone. Sci. Rep. UK 5

He, Q., Silliman, B.R., 2016. Consumer control as a common driver of coastal vegetation worldwide. Ecol. Monogr. 86, 278-294.

He, Q., Altieri, A.H., Cui, B.S., 2015. Herbivory drives zonation of stress-tolerant marsh plants. Ecology 96, 1318-1328.

He, Q., Silliman, B.R., Liu, Z.Z., Cui, B.S., 2017. Natural enemies govern ecosystem resilience in the face of extreme droughts. Ecol. Lett. 20, 194-201.

Holdredge, C., Bertness, M.D., Altieri, A.H., 2009. Role of crab herbivory in die-off of New England salt marshes. Conserv. Biol. 23, 672-679.

Jefferies, R.L., Jano, A.P., Abraham, K.F., 2006. A biotic agent promotes large-scale catastrophic change in the coastal marshes of Hudson Bay. J. Ecol. 94, 234-242.

Jia, S.H., Wang, X.G., Yuan, Z.Q., Lin, F., Ye, J., Hao, Z.Q., et al., 2018. Global signal of topdown control of terrestrial plant communities by herbivores. P. Natl. Acad. Sci. U. S. A. $115,6237-6242$.

Katz, D.S.W., 2016. The effects of invertebrate herbivores on plant population growth: a meta-regression analysis. Oecologia $182,43-53$

Knol, M.J., VanderWeele, T.J., 2012. Recommendations for presenting analyses of effect modification and interaction. Int. J. Epidemiol. 41, 514-520.

La Pierre, K.J., Joern, A., Smith, M.D., 2015. Invertebrate, not small vertebrate, herbivory interacts with nutrient availability to impact tallgrass prairie community composition and forb biomass. Oikos $124,842-850$.

Lan, S.Q., Zhang, L.W., Yi, H.P., Xu, C.L., Lu, F., Feng, G.H., et al., 2020. Food source and feeding habit of Helice tientsinensis from the common reed vegetation in high marsh of Yellow River Delta, China. Chin. J. Appl. Ecol. 31, 319-325.

Li, D.L., Ding, Y.Q., Yuan, Y., Lloyd, H., Zhang, Z.W., 2014. Female tidal mudflat crabs represent a critical food resource for migratory red-crowned cranes in the Yellow River Delta, China. Bird Conserv. Int. 24, 416-428.

Lotze, H.K., Lenihan, H.S., Bourque, B.J., Bradbury, R.H., Cooke, R.G., Kay, M.C., et al., 2006 Depletion, degradation, and recovery potential of estuaries and coastal seas. Science 312, 1806-1809.

Mortensen, B., Danielson, B., Harpole, W.S., Alberti, J., Arnillas, C.A., Biederman, L., et al., 2018. Herbivores safeguard plant diversity by reducing variability in dominance. J. Ecol. 106, 101-112.

Murdoch, W.W., 1966. Community structure population control and competition -a critique. Am. Nat. 100, 219-226.

Oksanen, L., 1988. Ecosystem organization - mutualism and cybernetics or plain darwinian struggle for existence. Am. Nat. 131, 424-444. 
Osland, M.J., Enwright, N., Stagg, C.L., 2014. Freshwater availability and coastal wetland foundation species: ecological transitions along a rainfall gradient. Ecology 95, 2789-2802.

Poore, A.G.B., Campbell, A.H., Coleman, R.A., Edgar, G.J., Jormalainen, V., Reynolds, P.L., et al., 2012. Global patterns in the impact of marine herbivores on benthic primary producers. Ecol. Lett. 15, 912-922.

Schultz, R.A., Anisfeld, S.C., Hill, T.D., 2016. Submergence and herbivory as divergent causes of marsh loss in Long Island Sound. Estuar. Coast 39, 1367-1375.

Silliman, B.R., van de Koppel, J., Bertness, M.D., Stanton, L.E., Mendelssohn, I.A., 2005. Drought, snails, and large-scale die-off of southern US salt marshes. Science 310, 1803-1806.

Silliman, B.R., McCoy, M.W., Angelini, C., Holt, R.D., Griffin, J.N., van de Koppel, J., 2013. Consumer fronts, global change, and runaway collapse in ecosystems. Annu. Rev. Ecol. Evol. S. 44, 503-538
Tang, N., Cui, B.S., Zhao, X.S., 2006. The restoration of reed (Phragmites australis) wetland in the Yellow River Delta. Acta Ecol. Sin. 26, 2616-2624.

UNEP, 2006. Marine and Coastal Ecosystems and Human Well-being: A Synthesis Report Based on the Findings of the Millennium Ecosystem Assessment. United Nations Environment Programme, Nairobi, Kenya.

Zhang, L.W., Wang, A.D., Zhao, Y.J., Chen, L., Song, J.B., Yang, C.Z., et al., 2018a. Genetic variation of Phragmites australis and its relationship with salinity in the coastal wetland of Yellow River Delta. Chin. J. Ecol. 37, 2362-2368.

Zhang, L.W., Wang, A.D., Zhao, Y.J., Song, J.B., Han, G.X., 2018b. The effects of crab herbivory on the growth of Phragmites australis seedlings in a high marsh of the Yellow River delta. Chin. J. Ecol. 37, 1065-1070. 